\title{
Molecular detection of Helicobacter pylori in oral samples from patients suffering digestive pathologies
}

\author{
Myriam-Lucrecia Medina ${ }^{1}$, Marcelo-Gabriel Medina ${ }^{2}$, Graciela-Teresita Martín ${ }^{3}$, Santiago-Omar Picón ${ }^{4}$, \\ Adriana Bancalari ${ }^{5}$, Luis-Antonio Merino ${ }^{6}$ \\ ${ }^{1}$ Course of Radiology. Faculty of Dentistry. Universidad Nacional del Nordeste. Corrientes. Argentina \\ ${ }^{2}$ Course of Microbiology, Parasitology and Immunology. Faculty of Medicine. Universidad Nacional del Nordeste. Corrientes. \\ Argentina \\ ${ }^{3}$ Teaching and Investigation Department. "Dr. Avelino Castelán” Pediatric Hospital. Resistencia. Argentina \\ ${ }^{4}$ Gastroenterology Service. "Dr. Julio C. Perrando" Hospital. Resistencia. Argentina \\ ${ }^{5}$ Pathological Anatomy Service. "Dr. Julio C. Perrando" Hospital. Resistencia. Argentina
}

Correspondence:

Cátedra de Microbiología, Parasitología e Inmunología

Facultad de Medicina

Universidad Nacional del Nordeste

Sargento Cabral

20013400 Corrientes. Argentina,

lamerino@gigared.com

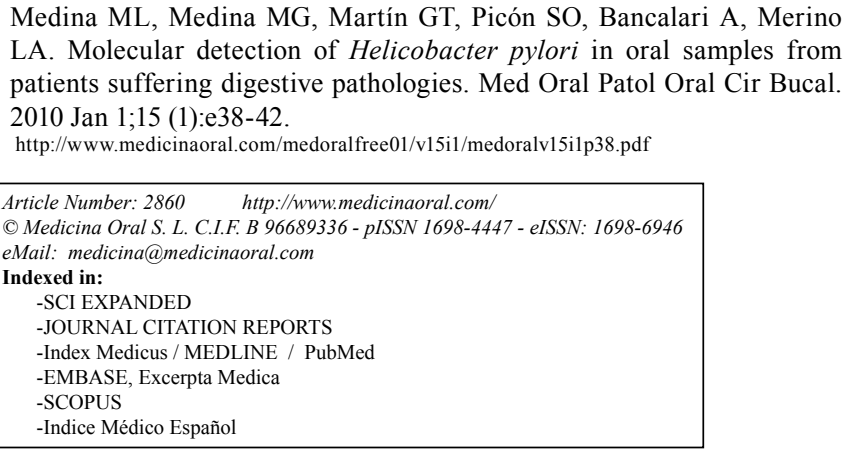

\begin{abstract}
Objective: to determine the simultaneous presence of $H$. pylori in both the oral cavity and gastric mucosal in patients suffering digestive pathologies and to establish the possible association between the presence of $H$. pylori in the oral cavity and the gingivoperiodontal pathology. Study design: Patients with gastric symptoms (case group) and asymptomatic patients (control group) seen at the Gastroenterology Department of Dr. Julio C. Perrando Hospital (Resistencia, Argentina) were selected. Dental plaque and saliva samples from both groups were obtained. In the case group, gastric biopsy samples were also taken. H. pylori was detected in gastric biopsies by histological stains, and Polymerase Chain Reaction (PCR) was carried out on the oral samples. Results: Among the 98 patients (43 cases and 55 controls), 196 oral samples (saliva 98, dental plaque 98) and 43 gastric biopsias were obtained. H. pylori was detected in oral samples in 18/98 patients, in gastric biopsies in 38/43 patients, and in both samples in 15/43 patients. Conclusions: The presence of $H$. pylori in the oral cavity of patients suffering digestive pathologies is more frequent in those patients harbouring a gingivoperiodontal disease, and this fact could represent an obstacle for the eradication of the bacterium. At the same time, it could constitute a risk factor for gastrointestinal reinfection after treatment.
\end{abstract}

Key words: Helicobacter pylori, saliva, dental plaque, digestive pathologies. 


\section{Introduction}

Helicobacter pylori (H. pylori) infection has a worldwide distribution with a greater likelihood of infection during childhood and its prevalence increases with age (1); additionally, it has been observed that its frequency decreases when sanitary conditions are improved (2). Globally, there are two basic epidemiological patterns that define its distribution: countries with peccary hygienic and sanitary conditions show high levels of infections during the childhood ranging from 70 to $80 \%$ (called countries or regions type 1), and more developed countries (called regions or countries type 2) where the infection shows an adult prevalence around $60 \%(2,3,4)$.

H. pylori infection is related with several clinic entities such as atrophic gastritis, gastric and duodenal ulcers, gastric MALT lymphoma, and gastric cancer (5); however, several aspects of the pathogenesis and epidemiology of these diseases remain unclear (6).

Various authors had reported the presence of $H$. $p y$ lori in the oral cavity and proposed that it could be the source for stomach infection and re-infection after an eradication therapy and that it could participate in the person to person transmission $(1,2,7)$.

It is mentioned that there are conditions that can facilitate the oral colonization by H. pylori, such as gastroesophageal reflux and poor hygiene, among others $(7,8)$; at the same time, there are authors who argue that cultural and living conditions can be decisive in the development of infection by this bacterium (1).

Due to the relationship between gastric symptoms and the presence of $H$. pylori in the oral cavity remains yet unclear and because its presence in oral cavity could be a likely reservoir of infection and re-infection, this work was performed to determine the simultaneous presence of $H$. pylori in both oral cavity and gastric mucosal from patients suffering digestive pathologies, and to establish the possible association between the presence of $H$. pylori in the oral cavity and the gingivoperiodontal pathology.

\section{Materials and Methods}

Patient selection: after informed consent, patients attending the Gastroenterology Service of "Dr. Julio C. Perrando" Hospital (Resistencia, Argentina) and fulfilling inclusion criteria were consecutively selected.

Inclusion criteria: symptomatic individuals with and without criteria for endoscopic gastric biopsy (cases and controls, respectively) were selected. These criteria were: recurrent abdominal pain, unexplained vomiting, weight loss and signs of organic gastroduodenal pathology.

Exclusion criteria: patients receiving antibiotics, $\mathrm{H} 2$ receptor antagonists or anti-acid treatment, were excluded. Sampling: in the anamnesis, the hygienic habits of the oral cavity were emphasized and the gingivoperiodontal status was valuated. In all patients, saliva and dental plaque samples were obtained from at least three differ- ent zones (interdentally, sub gingival and supragingival, from posterior vestibular and lingual zones) to minimize the effect of the oral irregular distribution. Dental floss was used to remove the dental plaque from the interdentally spaces and sterile curette was used to remove the supragingival plaque. Subsequently, the zone was washed with sterile saline solution and samples of subgingival plaque were obtained by using absorbent paper cones, which were left approximately 10 seconds. All samples were manipulated in strictly asepses conditions to avoid contamination with oral flora and placed individually in $0.3 \mathrm{ml}$ of phosphate buffered saline, ( $\mathrm{pH} 7.4$ ) for transport. To obtain saliva samples, patients were instructed for no sanitizing the mouth prior to the collection, six hours of fasting, and mouth washing with phosphate buffered saline ( $\mathrm{pH}$ 7.4), for further salivation in a sterile plastic collector. All samples from oral cavity were kept at $-20^{\circ} \mathrm{C}$ until their assessment by using Polymerase Chain Reaction (PCR). Additionally, antral and body stomach samples were obtained from the case group by gastric endoscopy.

All protocols applied were approved by the Hospital and Dentistry School Ethics Committees. Biological sample manipulation was made according to the Declaration of Helsinki criteria.

Samples processing: H. pylori detection in saliva and dental plaque was carried out in the Regional Medicine Institute (Universidad Nacional del Nordeste) by PCR technique. Primers for $H$. pylori urease (ure-A) were used (HPU1: 5' GCC AAT GGT AAA TTA GTT 3' and HPU2: 5' CTC CTT AAT TGT TTT TAC 3'), according methodology previously described (1). Briefly, the sample suspension was washed with phosphate buffered saline ( $\mathrm{pH}$ 7.4) and centrifuged at $12000 \mathrm{x}$ g for 3 minutes. The sediment was re-suspended in $500 \mu \mathrm{l}$ of $1 \%$ Triton buffer, boiled at $100^{\circ} \mathrm{C}$ for 15 minutes and centrifuges at $10000 \mathrm{x}$ g for 1 minute, and the DNA containing supernatant was used as template for PCR technique. Amplification was performed in a $50 \mu \mathrm{l}$ reaction final volume, using $10 \mu \mathrm{l}$ of the templated and $40 \mu \mathrm{l}$ of a mix reaction containing: $50 \mathrm{mM} \mathrm{KCl}, 20 \mathrm{mM}$ Tris-HCl, $\mathrm{pH} 8.3,3.0 \mathrm{mM} \mathrm{MgCl} 2,0.01 \% \mathrm{p} / \mathrm{v}$ gelatin, $2.5 \mathrm{U}$ Taq polymerase, $0.2 \mathrm{mM}$ dNTPs, $0.5 \mu \mathrm{M}$ primer HPU1 and $0.5 \mu \mathrm{M}$ primer HPU2. After one initial denaturalization step at $94^{\circ} \mathrm{C}$ for 4 minutes, 35 cycles were applied in one automatic thermal cycler. The cycles consisted of 3 steps of 1 minute each one: denaturalization at $94^{\circ} \mathrm{C}$, annealing at $45^{\circ} \mathrm{C}$ and extension at $72^{\circ} \mathrm{C}$. An additional extension step at $72^{\circ} \mathrm{C}$ for 5 minutes was applied. Of each amplified product, $12 \mu \mathrm{l}$ were mixed with $3 \mu \mathrm{l}$ of leading buffer provided by the Taq polymerase manufacturer and were electrophoresed on a 1.5\% agarose gel in Tris-Acetate-EDTA buffer ( $\mathrm{pH} \mathrm{8.4).} \mathrm{The} \mathrm{gel} \mathrm{was}$ stained with a $0.5 \mu \mathrm{g} / \mathrm{ml}$ Ethidium Bromide aqueous solution and examined under UV light. A sample was 
considered positive when one $411 \mathrm{bp}$ band was observed (Figure 1). As positive control, we used DNA obtained from a $H$. pylori strain (provided by the Department of Special Bacteriology at National Institute of Infectious Diseases ANLIS “Carlos G. Malbrán”) which was processed in the same way as the samples.

Gastric tissue samples were processed in the Laboratory of Pathological Anatomy of the "Dr. Julio C. Perrando" Hospital using the Hematoxylin-eosin staining in order to detect some tissue alterations and by Giemsa staining to visualize the bacteria; one sample was considered positive when showed curve or spiral shaped bacilli associated with the mucosa surface and within the mucus layer, with histological changes consistent with leukocyte infiltration (Figure 2).

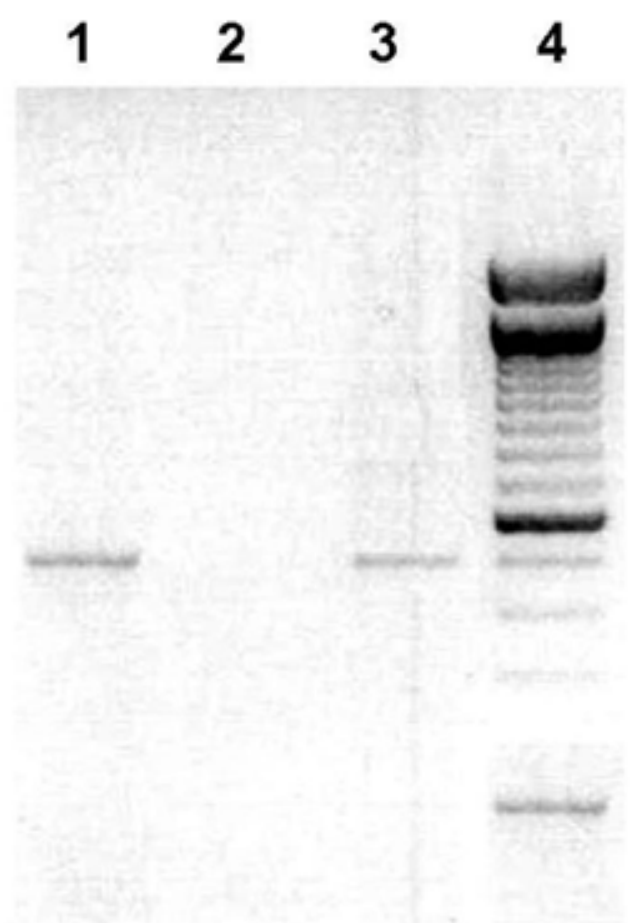

Fig. 1. Agarose gel electrophoresis showing bands with approximately 411 bp obtained by PCR using primers HPU1 and HPU2 for the urease gen (ureA) of Helicobacter pylori; Lane 1: positive dental plaque sample, Lane 2: negative control, Lane 3: positive control, Lane 4: $100 \mathrm{bp}$ molecular weight marker.

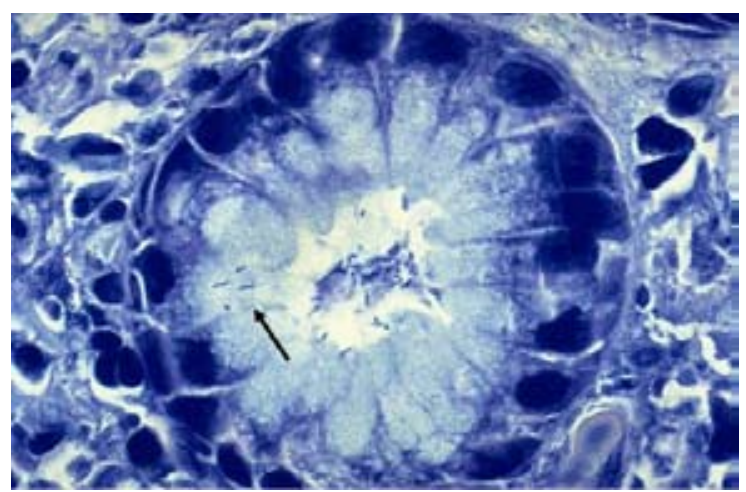

Fig. 2. Positive sample of antral tissue stained with Giemsa showing some spiral shaped bacteria compatible with Helicobacter pylori $(\longleftarrow)$.

Statistical analysis: Data obtained were processed using the EpiInfo software. With quantitative variables, the percentage was used to calculate the frequencies and the arithmetical mean was used for the central tendency measures. To describe the association between qualitative variables, the chi square method was applied and a value of $\mathrm{p}<0.05$ was taken as significant.

\section{Results}

In this work, 98 patients were selected, 43 cases and 55 controls. Among these, $59(60.2 \%)$ were females and $(39.8 \%)$ were males. The patients' ages ranged from 5 to 78 years $($ mean $=43.7$ years).

One hundred and ninety six samples from oral cavity (98 saliva and 98 dental plaque) and 43 gastric biopsy samples were collected.

H. pylori was detected in 38/43 (88.4\%) gastric samples, in $18 / 98(18.4 \%)$ oral samples, and in $15 / 43$ (34.9\%) patients it was detected in both kind of samples.

Among the control group, only 3 patients were positives for $H$. pylori in oral cavity ( 2 in dental plaque and 1 in saliva).

The age of patients with positive biopsies ranged from 5 to 78 years $($ mean $=43.5)$ and the ages of patients with positive oral samples ranged from 9 and 76 years (mean $=48.5$ ).

Table 1. Correlation between the presence of H. pylori in oral samples and gastric biopsies.

\begin{tabular}{|c|c|c|c|c|}
\hline \multirow{2}{*}{ Samples } & \multicolumn{2}{|c|}{$\begin{array}{c}\text { Presence of } \boldsymbol{H} \text {. pylori } \\
\text { in gastric biopsies }\end{array}$} & \multirow{2}{*}{ P value } \\
\cline { 2 - 4 } & Positive & Negative & \\
\hline \multirow{3}{*}{$\begin{array}{c}\boldsymbol{H} \text {. pylori } \\
\text { PCR-positive }\end{array}$} & Dental plaque & 7 & 2 & 0.004 \\
\cline { 2 - 5 } & Saliva & 7 & 1 & 0.002 \\
\cline { 2 - 5 } & Dental plaque + Saliva & 1 & 0 & - \\
\hline & Total & 15 & 3 & - \\
\hline
\end{tabular}


Table 2. Relationship between oral indicators and colonization by Helicobacter pylori.

\begin{tabular}{|c|c|c|c|}
\hline \multirow[t]{2}{*}{ Indicator } & \multicolumn{2}{|c|}{$\begin{array}{c}\text { Detection of } \boldsymbol{H} \text {. pylori in oral cavity } \\
\text { N (\%) }\end{array}$} & \multirow[t]{2}{*}{$P$ value } \\
\hline & Positive $(\mathrm{N}=18)$ & Negative $(N=80)$ & \\
\hline \multicolumn{4}{|l|}{ Dental prosthesis types } \\
\hline \multirow{5}{*}{$\begin{array}{l}\text { Fixed } \\
\text { Metallic Partially Removable } \\
\text { Acrylic Partially Removable } \\
\text { Complete } \\
\text { None }\end{array}$} & $1(5.6)$ & $5(6.3)$ & 0.7 \\
\hline & 0 & $4(5)$ & 0.4 \\
\hline & $4(22.2)$ & $13(16.3)$ & 0.4 \\
\hline & $1(5.6)$ & $1(1.3)$ & 0.3 \\
\hline & $12(66.7)$ & $57(71.3)$ & 0.7 \\
\hline \multicolumn{4}{|l|}{ Daily frequency of teeth brushing } \\
\hline \multirow{3}{*}{$\begin{array}{l}\text { None } \\
\text { 1-2 times } \\
3 \text { or more times } \\
\end{array}$} & $1(5.6)$ & $8(10)$ & 0.5 \\
\hline & $12(66.7)$ & $49(61.3)$ & 0.6 \\
\hline & $5(27.8)$ & $23(28.8)$ & 0.5 \\
\hline \multicolumn{4}{|l|}{ Gingivoperiodontal status } \\
\hline \multirow{4}{*}{$\begin{array}{l}\text { Absence of dental pieces } \\
\text { Periodontitis } \\
\text { Gingivitis } \\
\text { Normal }\end{array}$} & 0 & $3(3.8)$ & 0.5 \\
\hline & $9(50)$ & $35(43.8)$ & 0.6 \\
\hline & $4(22.2)$ & $7(8.8)$ & 0.1 \\
\hline & $5(27.8)$ & $35(43.8)$ & 0.3 \\
\hline
\end{tabular}

The correlation between the positivity for H. pylori in oral and gastric samples (Table 1) was statistically significant $(\mathrm{p}=0.004$ for dental plaque/biopsy and $\mathrm{p}=$ 0.002 for saliva/biopsy).

H. pylori was detected in gastric biopsies from 23 women and from 15 men $(\mathrm{p}=0.96)$ and in oral cavity from 10 women and 8 men $(\mathrm{p}=0.65)$

Table 2 shows those indicators considered to evaluate the oral colonization by $H$. pylori.

\section{Discussion}

Infection by $H$. pylori remains as one of the most important scientific phenomena in the biomedical literature worldwide and represents the most prevalent chronic bacterial disease of the world because it affects more than half of the world population, with a distribution related to the degree of economic development in each country (9). In developing countries, the prevalence of H. pylori infection may reach $80-90 \%$ of the total population $(2,4)$; nevertheless, no more than the $3 \%$ of these individuals will present symptoms or clinical manifestations attributable to the infection (5). Because the presence or absence of the infection in relation with the different alleles in H. pylori can not explain the different rates of illness according on the patients' ages and geographical location, the key of the variable distribution of illness in the population could reside in an interaction between the environment, the bacterium and the patient $(2,10)$.

For all mentioned above, there is an increasing interest for generating different non invasive diagnostic tests which allow the study of prevalence and incidence of H. pylori.

Among the Biology Molecular Techniques, Polymerase Chain Reaction (PCR) has demonstrated to be specific and sensible, that is why it is considered the method of choice to detect DNA from $H$. pylori in the oral cavity and for clinical control and follow-up of the patients $(1,7,11)$. It has been used also in a wide range of ages, in which the diagnostic criteria by endoscopic examination were imprecise (12).

In this work, the frequency of $H$. pylori was higher in gastric biopsies than in dental plaque, in agreement with those published by other authors, who detected the bacterium in $18 \%$ of dental plaques studied (13).

Although the detection rate in the oral cavity in this study was low, the microorganism was detected with values similar to those published by other researchers $(7,13)$ who have not been able to demonstrate the presence of bacteria or that have detected it in very low percentages (14).

In the control group the microorganism was detected in mouth in a smaller percentage than in those patients who had gastrointestinal symptoms, which is in agreement with literature data (1). For this reason, the authors recommend the $H$. pylori searching in the oral cavity as an auxiliary tool for the diagnosis of infection by this organism (15).

Also, it is believed that gastric infection by $H$. pylori often occurs with simultaneous presence of the pathogen in dental plaque $(16,17)$. However, the relationship between gastric symptoms and the presence of $H$. pylori in the oral cavity is not clear (8). Our findings regar- 
ding the positive correlation of $H$. pylori in gastric biopsies and oral samples were statistically significant and these results coincide with those published in literature, indicating that in many cases, patients with positive results of gastric biopsies were also positive in dental plaque (18). The simultaneous presence of $H$. pylori in oral samples and gastric biopsies would lend those expressed by some studies about the possibilities of reinfection $(19,20)$.

While some studies have shown higher frequency of $H$. pylori in dental plaque (15), this paper has identified the bacteria in similar proportions in dental plaque and in saliva samples. However, according to the literature, the results depend largely on the detection method chosen (11).

In patients with positive biopsies for $H$. pylori, the difference between sexes was not statistically significant. These results are in agreement with those that postulate the lack of an evidence about the influence of sexes in the bacterium acquisition $(1,15)$.

Female predominated within patients with positive samples for $H$. pylori in oral samples, although the differences were not statistically significant. When viewing results of other authors, the results regarding the prevalence of colonization according to sex are very variable $(1,15)$.

The mean age of patients with positive biopsies for $H$. pylori coincided with those reported by other authors, who noted that while there is a greater chance of infection during childhood, its prevalence increases with age. The average age of patients with positive oral samples for $H$. pylori did not differ from those reported by other studies $(1,15)$.

According to some authors, there are conditions that can facilitate the oral colonization by $H$. pylori, such as gastroesophageal reflux, the use of dentures and poor hygiene habits, among others (8), however, others mentioned that there was no relationship between the use of dentures and the increase in the prevalence of $H$. pylori (19), which coincided with the results of this investigation.

Additionally, it has been proposed that the colonization in dental plaque does not become in a local disease (9); however, some authors found a high prevalence of $H$. pylori in dental plaque from patients suffering periodontitis (7). In the present work, although not significantly, it was observed that patients with positive $H$. pylori in oral cavity showed mostly some kind of gingivoperiodontal disease (20).

The presence of $H$. pylori in oral cavity of patients suffering digestive pathologies is more frequent in those harboring some gingivoperiodontal disease, and this fact could represent an obstacle for the eradication of the bacterium, at the same time it could constitute a risk factor for gastrointestinal reinfection after treatment.

\section{References}

1. Berroteran A, Perrone M, Correnti M, Cavazza ME, Tombazzi C, Goncalvez R, et al. Detection of Helicobacter pylori DNA in the oral cavity and gastroduodenal system of a Venezuelan population. J Med Microbiol. 2002;51:764-70.

2. Cave DR. Epidemiology and transmission of Helicobacter pylori infection. How is Helicobacter pylori transmitted? Gastroenterology. 1997;113:9-13.

3. Clearfield HR. Helicobacter pylori: aggressor or innocent bystander? Med Clin North Am. 1991;75:815-29.

4. Suerbaum S, Michetti P. Helicobacter pylori infection. N Engl J Med. 2002;347:1175-86.

5. Correa P. Helicobacter pylori as a pathogen and carcinogen. J Physiol Pharmacol. 1997;48 Suppl 4:19-24.

6. Atherton JC. The clinical relevance of strain types of Helicobacter pylori. Gut. 1997;40:701-3.

7. Umeda M, Kobayashi H, Takeuchi Y, Hayashi J, MorotomeHayashi Y, Yano K, et al. High prevalence of Helicobacter pylori detected by PCR in the oral cavities of periodontitis patients. J Periodontol. 2003;74:129-34.

8. Gardner JD, Perdomo C, Sloan S, Hahne WF, Barth JA, Rodriguez-Stanley S, et al. Integrated acidity and rabeprazole pharmacology. Aliment Pharmacol Ther. 2002;16:455-64.

9. Marshall BJ. Helicobacter pylori. Am J Gastroenterol. 1994;89:S116-28.

10. Araya JC, Anabalón L, Roá I, Bravo M, Villaseca MA, Guzmán $\mathrm{P}$, et al. Association between Helicobacter pylori genotype and the severity of gastritis in infected adults. Rev Med Chil. 2004;132:134554.

11. Song Q, Haller B, Ulrich D, Wichelhaus A, Adler G, Bode G. Quantitation of Helicobacter pylori in dental plaque samples by competitive polymerase chain reaction. J Clin Pathol. 2000;53:218-22.

12. Chelimsky G, Czinn S. Peptic ulcer disease in children. Pediatr Rev. 2001;22:349-55.

13. Chumpitaz Conde J, Gutiérrez Manay J, Córdova Acosta R, Sánchez Medina M, Vásquez Valverde N, Rivadeira Malaga C, et al. Isolation of helicobacter pylori in dental plaque in patients with gastritis at "Angamos" clinic. Rev Gastroenterol Peru. 2006;26:373-6.

14. Okuda K, Ishihara K, Miura T, Katakura A, Noma H, Ebihara Y. Helicobacter pylori may have only a transient presence in the oral cavity and on the surface of oral cancer. Microbiol Immunol. 2000;44:385-8.

15. Chitsazi MT, Fattahi E, Farahani RM, Fattahi S. Helicobacter pylori in the dental plaque: is it of diagnostic value for gastric infection? Med Oral Patol Oral Cir Bucal. 2006;11:E325-8.

16. Dowsett SA, Archila L, Segreto VA, Gonzalez CR, Silva A, Vastola KA, et al. Helicobacter pylori infection in indigenous families of Central America: serostatus and oral and fingernail carriage. J Clin Microbiol. 1999;37:2456-60.

17. Gebara EC, Faria CM, Pannuti C, Chehter L, Mayer MP, Lima LA. Persistence of Helicobacter pylori in the oral cavity after systemic eradication therapy. J Clin Periodontol. 2006;33:329-33.

18. Miyabayashi H, Furihata K, Shimizu T, Ueno I, Akamatsu T. Influence of oral Helicobacter pylori on the success of eradication therapy against gastric Helicobacter pylori. Helicobacter. 2000;5:30-7.

19. Hardo PG, Tugnait A, Hassan F, Lynch DA, West AP, Mapstone NP, et al. Helicobacter pylori infection and dental care. Gut. 1995;37:44-6.

20. Cheng LH, Webberley M, Evans M, Hanson N, Brown R. Helicobacter pylori in dental plaque and gastric mucosa. Oral Surg Oral Med Oral Pathol Oral Radiol Endod. 1996;81:421-3. 